\title{
Factor VIII inhibitor assay using skin puncture blood samples
}

\author{
R F Hinchliffe, G J Bellamy, J S Lilleyman
}

\begin{abstract}
A method was developed for the measurement of factor VIII inhibitors by the Bethesda technique using small volumes of skin puncture blood. Human and porcine inhibitor concentrations on paired venous and skin puncture samples measured on 10 occasions were highly correlated, with no significant difference between them. Assays on four inhibitor negative haemophiliac patients were also negative by the skin puncture method. Sample dilution at the collection stage results in loss of sensitivity to inhibitor concentrations below 1 unit/ml, but the technique will be of value in monitoring higher concentrations when venous access is difficult and must be saved for parenteral treatment.
\end{abstract}

About $12^{\circ}{ }_{0}$ of patients with haemophilia A develop neutralising antibodies to infused factor VIII, and repeated laboratory measurement of such inhibitor activity plays an essential part in the clinical management of major bleeding episodes. Inhibitor assays are conventionally performed on venous blood which is often very difficult to obtain from young haemophiliac patients, and repeated attempts at venepuncture can damage veins needed for parenteral treatment. We have developed an assay that can be performed using small volumes of diluted skin puncture blood.

\section{Methods}

Blood obtained by skin puncture $(0.2 \mathrm{ml})$ (thumb prick) was taken into each of two $0.4 \mathrm{ml}$ flip-top microcentrifuge tubes (Laboratory Sales Ltd, Rochdale, Lancaster) containing $0 \cdot 2$ $\mathrm{ml}$ of citrated barbitone-saline buffer (trisodium citrate $0.35 \mathrm{~g}$; barbitone sodium $0.21 \mathrm{~g}$; sodium chloride $1.01 \mathrm{~g}$; dissolved in a final volume of $100 \mathrm{ml}$ of distilled water after $\mathrm{pH}$ adjustment to $7 \cdot 35$ with IN hydrochloric acid). About $0.2 \mathrm{ml}$ of blood was also taken into a miniaturised EDTA tube (Teklab) for measurement of haematocrit. Venous samples were collected at the same time into HEPEScitrate and EDTA. Informed consent was obtained from each patient, or his parents where appropriate.

The paired inhibitor samples were separated and assayed by the Bethesda technique, ${ }^{1}$ either immediately, or after storage for up to one week at $-25^{\circ} \mathrm{C}$. Skin puncture samples were adsorbed with one twentieth volume of aluminium hydroxide gel before testing and diluted, depending on the patient's previous inhibitor concentration. Venous samples were treated in the standard way. Stored pooled normal plasma and reconstituted porcine factor VIII (Speywood) adjusted to a level of one unit $/ \mathrm{ml}$ were used as sources of factor VIII. After a two hour incubation period residual factor VIII was measured by a standard two-stage method using commercially available reagents (Diagnostic Reagents, Thame, Oxfordshire).

Inhibitor concentrations derived from the Bethesda chart were corrected, if necessary, for sample dilution and further corrected to account for the effects of haematocrit and dilution with anticoagulant. For skin puncture samples, the following formula was used:

$$
\frac{1+(1-\text { haematocrit })}{(1-\text { haematocrit })} \text {. }
$$

\section{Results}

Human and porcine factor VIII inhibitor concentrations were obtained on paired samples on 10 occasions from three patients with severe haemophilia, aged 1-3 years, who were known to have inhibitors. One patient was tested on six occasions. Results are shown in the table. Paired values were highly correlated ( $r=0.98$ for both human and porcine assays) with no significant differences between them. Paired samples from four patients with severe haemophilia, known not to have inhibitors, gave negative results by skin puncture assay. Paired samples were assayed in the same batch; this, together with the post-assay manipulations required to account for dilution factors and haematocrit, prevented observer bias. On one occasion (case 1, first sample) aliquots of adsorbed venous and skin puncture samples were frozen and assayed again at a later date (table).

Paired venous and skin puncture factor VIII inhibitor activity expressed in Bethesda units

\begin{tabular}{|c|c|c|c|c|}
\hline \multirow[b]{2}{*}{$\begin{array}{l}\text { Case } \\
\text { No }\end{array}$} & \multicolumn{2}{|l|}{ Human } & \multicolumn{2}{|l|}{ Porcine } \\
\hline & $\begin{array}{l}\text { Venous } \\
(\mathrm{u} / \mathrm{ml})\end{array}$ & $\begin{array}{l}\text { Skin puncture } \\
(u / m l)\end{array}$ & $\begin{array}{l}\text { Venous } \\
(u / m l)\end{array}$ & $\begin{array}{l}\text { Skin puncture } \\
(u / m l)\end{array}$ \\
\hline 1 & 26 & 24 & $4 \cdot 2$ & $4 \cdot 4$ \\
\hline- & $19^{\star}$ & $21^{\star}$ & $6^{\star}$ & $6^{\star}$ \\
\hline- & 22 & 25 & 6 & 5 \\
\hline- & 15 & 13 & $4 \cdot 2$ & $3 \cdot 1$ \\
\hline- & 13 & 13 & 4.9 & 6 \\
\hline- & 29 & 30 & 17 & 17 \\
\hline- & 20 & 22 & 14 & 17 \\
\hline 2 & $4 \cdot 3$ & 5 & 0.9 & 0 \\
\hline- & $3 \cdot 3$ & 3.8 & 0.7 & 0 \\
\hline- & 9 & 8 & 3.7 & $3 \cdot 7$ \\
\hline 3 & 0 & 0 & 0.8 & 1.6 \\
\hline
\end{tabular}

$\star$ Repeat assay on first sample 


\section{Discussion}

Our findings indicate that this simple modification of the factor VIII inhibitor assay can reliably reproduce the results obtained with venous samples. False positive results were not found in the four inhibitor negative patients tested. In practice care must be taken to obtain a free flow of blood, as clotting may occur if samples are taken slowly. Immersing the hand in warm water for several minutes before sampling can help.

The sensitivity of the assay is affected by the dilution factor which is, to some extent, dependent on haematocrit being 3 at a haematocrit of 0.5 , and 2.3 at a haematocrit of 0.3 . In this study haematocrit values were usually in the range $0.3-0.35$, giving a lower detection limit around one Bethesda unit $/ \mathrm{ml}$. This was borne out in two porcine assays, when concentrations of 0.9 and $0.7 \mathrm{units} / \mathrm{ml}$ were not detected by the skin puncture method. The modification of using four parts of patient sample to one part of factor VIII at the incubation stage to improve sensitivity ${ }^{2}$ was not used in this study, but might prove useful provided sufficient sample is available. The dilution factor introduced at collection must also be considered when calculating the dilution of sample required at the incubation stage.
The small volume of sample available prevented a detailed study of the precision of the skin puncture method, although results were satisfactory on the one occasion that assays were repeated. In a collaborative study Austen et al found variable within laboratory precision with both Bethesda and New Oxford methods, coefficients of variation (CV) for the former varying from $0-37 \%{ }^{3}$ There was considerably more variation among laboratories (CV 37-78\%) and a call for a standard antibody sample was made. Given due care to sample collection and assay technique, there is no reason to suppose that the precision of the skin puncture method is inferior.

This method should be of value in monitoring inhibitor concentrations in young and older patients with haemophilia with difficult veins, although venous blood remains the sample of choice in detecting the presence of inhibitors at concentrations of less than one unit $/ \mathrm{ml}$.

1 Kasper CK. A more uniform measurement of factor VIII inhibitors. Thromb Diath Haem 1975;34:869-72.

2 Hall R, Malia RG. Medical laboratory haematology. London: Butterworths, 1984:593.

3 Austen DEG, Lechner K, Rizza CR, Rhymes IL. A comparison of the Bethesda and New Oxford methods of factor VIII antibody assay. Thromb Haemostas 1982;47:72-5. 